\title{
La perversión política en el Perú: Un análisis intersubjetivo de la corrupción
}

\author{
Jerjes Loayza Javier*
}

\author{
Nivel: Comunicado \\ Fecha de recepción: 20 de julio de 2011 \\ Fecha de aprobación: 19 de agosto de 2011
}

\begin{abstract}
Resumen
El artículo analiza los actos de corrupción e inmoralidad de diversa índole a manos de los parlamentarios peruanos en los años 2007-2010, para lo cual se propone el análisis tanto de los representantes políticos, como de los ciudadanos. Para analizar dichos fenómenos se parte de un marco teórico que incumbe la intersubjetividad en la política en torno a lo simbólico y lo emotivo. Si bien el infractor comete actos inicuos, tipificados por su ilegalidad e inmoralidad, éste pensaría, que dichas prácticas son inofensivas, más aun, beneficiosas. Serían injustas sólo al descubrirse. Tanto lo injusto, como lo beneficioso, se vincularían y se reforzarían en este tipo de prácticas. Asimismo, la ciudadanía, al verse prefigurada por actos ilegales, figurarían a su vez, contextos en los que tolerarían y hasta retroalimentarían dicho proceso, pervirtiendo la política.
\end{abstract}

Palabras clave: Congreso, corrupción y magma de significaciones.

\begin{abstract}
The present article analyzes acts of corruption and inmorality commited by some peruvian congressmen between the years 2007 and 2010. For this porpuse the analisis will be made upon said congressmen and also on the citizens which they supposedly represent. To analyze this problem we will start from a theoretical framework that contains the intersubjectivity in politics around simbolism and emotivism. Although the offender commits iniquitous acts typified by their immorality and unlawfulness, he or she might consider them to be innocuous and, moreover, beneficial. They would be unfair only if they are uncovered. Both the unfair and beneficial elements would be vinculated with each other and would reinforce themselves in this kind of practices. Since the citizenry is foreshadowed by these illegal acts, it might conceive and allow contexts in which said acts are tolerated, and even give feedback onto this relation.
\end{abstract}

Key Words: Congress, corruption, magma of meanings.

* Egresado de la Maestría de Sociología con mención en Estudios Políticos, Licenciado en Sociología, Abogado. Universidad Nacional Mayor de San Marcos y Universidad Ricardo Palma, Lima, Perú. mxerxeslj@gmail.com 


\section{Introducción}

Las prácticas políticas por parte de los parlamentarios y la injusticia que de éstas se puede desprender, se convierten en una constante cuya cotidianidad se comprueba en titulares de radio, televisión y prensa escrita. Una serie de características perversas e infames enturbian la posibilidad de pretender la institucionalidad democrática de la política en el Perú. Sin embargo, muchos legisladores no lo piensan así. Poseen un doble discurso que les hace emitir solemnes promesas pero sus acciones reflejan poco de lo dicho, siendo más que contradictorias, incoherentes y paradójicas.

Todo esto me lleva a la hipótesis de la relación entre lo injusto y lo inofensivo de la política nacional, para poder comprender el panorama político en los últimos años, con especial énfasis en la máxima institución de un país: el Congreso de la República. Por un lado, las acciones inicuas parlamentarias menoscaban las posibilidades de una democracia representativa y una inclusión de la sociedad civil en los destinos del país, la cual se siente traicionada o simplemente ajena a todo proceso político nacional. Por otro lado -aunque no muy lejos- dichas acciones resultan ser inofensivas y beneficiosas desde la perspectiva de su infractor: no siente que hace algo eminentemente negativo, por el contrario sería un modo de beneficiarse a sí mismo, sacrificando de algún modo el capital simbólico del Congreso en la medida que sea descubierto o descubierta. Por ello, propongo el análisis desde la inteligencia de las emociones de la práctica de la corrupción e inmoralidad política, por parte de quienes la practican, y el juicio ético por parte de los ciudadanos y ciudadanas y su rol en la perversión ética de la política en el Perú.

Para tales objetivos, considero la política desde perspectivas intersubjetivas que alienten la comprensión de las principales emociones de la sociedad peruana y su relación con la política como imaginario social. Siendo diversos los momentos en que 
este concepto se reconfigura, se plantean reflexiones para el análisis de las resignificaciones simbólicas y valorativas de lo político a través del análisis de los eventos más representativos de inmoralidad y corrupción entre los años 2007-2010.

\section{La desvalorización de la institucionalidad de la democracia representativa en el Perú y la importancia de las emociones}

A pesar que la institución política le daría al ciudadano la oportunidad de reconocer su experiencia cotidiana como parte de la vida en sociedad (Lechner, 2002:12), en los últimos años, Latinoamérica pasa por una significativa caída de la centralidad de los partidos políticos, afectados por la desvalorización del congreso, como espacio público por excelencia, así como por la pérdida de importancia de los congresistas y de la relación elector/elegido (Calderón, Hopenhayn, Ottone, 1996:53). Circunstancia negativa si se considera que los partidos establecían principios de encuentro y de escisión, planteaban proyectos que a veces se entremezclaban con adhesiones sentimentales, creaban referentes y en algunos casos criterios de identificación (Grompone, 1999:52). América Latina se convierte en una permanente descomposición y recomposición de las identidades políticas (Lechner, 1988: 19). En cuanto al Perú, la debilidad de la institucionalidad de los partidos políticos se explicaría por la falta de tradición democrática y constitucional, la cual es precaria, elitista y poco representativa (Planas, 2000:401). La democracia resulta ser un sistema imperfecto, lleno de limitaciones e injusticias, que condice a amplios sectores populares y a reflexivos intelectuales, así como empresarios deseosos de eficiencia, a no sentirse identificados con un régimen tan defectuoso que está muy lejos de ser una "democracia real" (Arias, 1996: 58). Ello trae como consecuencia que exista, a lo largo de la historia peruana, una clara tradición de antipartidos o, peor aun, un sentimiento antipolítico, nutrido de la insistente propaganda de legitimación propalada por los diversos regíme- 
nes dictatoriales ${ }^{1}$ que se conserva en el ambiente, perjudicando la futura consistencia de los partidos y la propia estabilidad del sistema (Planas, 2000: 400).

Lo más preocupante es que se comprueba en nuestra historia que una coyuntura de caos y corrupción suele exigir personalidades autoritarias en el poder que simbolicen el orden, la sanción e inflexibilidad (Molinari, 2006: 19), menoscabando, de ese modo, la representatividad de los partidos políticos que vienen a comportarse como una suerte de "madrastra" de la democracia (Vargas-Machuca, 2008:156). Como sostiene Cansino (2008: 175), la democracia se inventa permanentemente desde la acción social, en los espacios públicos, pues la política no acaba en la institución o en la representación. Este autor propone una innovadora mirada, en que la democracia no es facticidad o empiria sino un símbolo, representando un potencial de reflexión social de carácter inconsciente, libre de todo monopolio de su espacio simbólico (Cansino, 2008:176). Los partidos ya no aparecen portadores de grandes relatos y proyectos de largo alcance, no parecen constituir un espacio de ciudadanía, de formación cívica y de ámbito de sociabilidad pública (Calderón, Hopenhayn, Ottone, 1996: 53). Las ansiedades ciudadanas mellan cada vez más la institucionalidad de la democracia representativa, la cual -se supone- tiene un mayor alcance moral por su mejor disposición para fomentar la responsabilidad, tratar la complejidad y el pluralismo, así como favorecer la deliberación deliberativa (Vargas-Machuca, 2008:161). Ese fracaso parcial se ve seriamente intensificado al volver la mirada a los que propagan esta inseguridad: los representantes políticos. Como bien explica VargasMachuca, las instituciones y tanto las motivaciones como pautas de comportamientos de los sujetos implicados, se condicionan

1 Planas(2000:41) reconocela paradoja en la cual las dictadurasimputan a los partidos defectos institucionales como verticalidad, autoritarismo, decisiones inconsultas, entre otras, que son características que las propias dictaduras contienen. 
entre sí. Las primeras, si funcionan adecuadamente, tienden a fomentar disposiciones congruentes con las razones que las justifican, mientras que los buenos hábitos contribuyen a estabilizar la calidad de las instituciones; si no es así, estas experimentan una suerte de entropía que les hace perder progresivamente su pujanza originaria (Vargas-Machuca, 2008:164).

A esta situación estructural le sumamos la lógica de sus actores, tanto de los representantes políticos elegidos como de los ciudadanos y ciudadanas electores. Estos últimos tienen el papel de criticar, y los primeros el de ser criticados. Durante el último periodo congresal 2006-2011, se han suscitado una serie de escándalos y eventos bochornosos, no sólo vinculados a la corrupción, sino a la indecencia moral de quienes detentan el poder legislativo.

Así, el fenómeno de la corrupción provoca una creciente disminución de la institucionalidad de los partidos políticos en el Perú. El 56\% de ciudadanos opina que el principal problema que enfrenta el Estado y que impide el desarrollo del país es la corrupción ${ }^{2}$, creciendo en comparación al año 2006 (30\%) y el año $2008(37 \%)$.

Asimismo, el Congreso fue considerado la institución más corrupta del país, con un $46 \%$. Un $61 \%$ cree que el legislador de su región no ha hecho nada por ellos ${ }^{3}$. Finalmente al 52\% de peruanos le interesaría poco o nada la política4. Esta "crisis de representación" reflejaría lo poco que la política ha hecho para nombrar e interpretar los problemas de los ciudadanos: la brecha que se abre entre sociedad y política tiene que ver con las dificultades de acoger y procesar la subjetividad (Lechner,

2 Encuesta realizada por Ipsos Apoyo Opinión y Mercado S.A. entre el 14 de mayo y el 6 de junio del 2010.

3 Encuesta realizada por CPI entre el 5 y el 9 de diciembre del 2009.

4 Encuesta realizada por Ipsos Apoyo Opinión y Mercado S.A. entre el 13 y el 16 de abril del 2010. 
2002:12). Habiendo mencionado la subjetividad en las ciencias políticas, si en adelante limitamos la política como una estancia quieta y uniforme cortaríamos de inicio nuestro debate -como algunos analistas suelen hacer-. Es necesaria una nueva concepción de la política que, según explicita Lechner, sea capaz de enfocar los cambios en marcha (Lechner, 2002: 24), diremos nosotros, las transiciones constantes en movimiento perenne. Como aseguró Sartori, la ciencia política se fue encaminando a lo que se calificaría como el culto al dato inútil y la trivialización de los saberes (Cansino, 2008: 33). Cansino propone:

Concebir lo político no como una parte del todo social, sino como el horizonte mismo de sentido social, o lo que es lo mismo, implica tratar de develar el entramado de relaciones y vivencias que conforma la experiencia social de los ciudadanos (Cansino, 2008:9).

Para comprender el debate de lo político en el imaginario social, es necesario partir de sus principales protagonistas, los ciudadanos: electores y detractores al mismo tiempo, conservadores por momentos e irreverentes por otros, volátiles y contradictorios, siendo, por ello, poco recomendable pretender categorizarlos áridamente ${ }^{5}$. Si bien es cierto el ciudadano demuestra ser itinerante en sus opiniones y en su modo de ver la política, es cierto también que la itinerancia no es meramente transitoria sino una condición permanente, no es una contingencia capaz de soslayar, sino una forma de ser que nos "instala" en la permanente movilidad entre enraizamiento y despedida (López,

5 Castoriadis critica duramente las categorías, considerándolas como elementos relacionados irremediablemente a una naturaleza determinada, de la cual dependen en todo sentido: La categoría es regla de vinculación de lo que se da: la unidad significa exhortación a pensar lo que se da bajo el punto de vista de lo "uno", la sustancia significa la exhortación a pensar en ello lo "permanente", lo "duradero", lo "persistente", o "aquello que no se puede predicar de otra cosa", y así sucesivamente. Bien mirado, estas exhortaciones no son nunca tales si no es en la medida en que valen, $y$, en su funcionamiento concreto, sólo valen en cuanto a [...] únicamente en cuanto a [...] una cosa cualquiera es, por ejemplo, una [...]. (Castoriadis, 1989: 158) 
2007: 26). Es hora de asimilar la política a las manifestaciones de los grupos que no tienen recursos para expresar su malestar de otra manera que no sea la transgresión (Grompone, 1999:54).

Urge buscar e incluso crear nuevas posibilidades de comprensión del fenómeno de la representatividad política y de su indiscutible calvario a manos de la incredulidad ciudadana. Los enfoques duros poco han hecho para otorgar luces a tales maleficios contemporáneos. Como punto de partida yace la desacralización de la política, que significaría la posibilidad de someter a la discusión pública problemas tratados anteriormente a través de monopolios interpretativos como el ejercido por la Iglesia (Cansino, 2008:74), la inmoralidad debe ser un tema que permita la comprensión del proceso de despolitización de la sociedad.

Para comprender el fenómeno de las prácticas negativas de los legisladores, proponemos una aproximación al vínculo entre sus motivaciones y sus emociones. Me refiero a una relación cercana entre la práctica política y la aparente creencia de que tal práctica no tiene por qué ser negativa, al menos no para su infractor. Situamos como principal paradigma a la "inteligencia" de las emociones.

Esta categoría produciría gran parte de nuestros actos conformando el paisaje de nuestra vida mental y social, imprimiendo a nuestras vidas un carácter irregular, incierto y proclive a los vaivenes (Nussbaum, 2008:21). Así, al estar las emociones imbuidas de inteligencia y discernimiento, contienen en sí mismas conciencia de valor e importancia, por lo cual no pueden dejarse fácilmente a un lado a la hora de dar cuenta del juicio ético (Nussbaum, 2008: 21).

Gracias a las luces teóricas que nos otorga Nussbaum, podemos aproximarnos a los móviles que llevan al parlamentario a cometer actos que pueden ir en consonancia con una actitud carente de juicio ético, invisibilizando a quienes representan en su labor de legisladores de la República. Introducir las emociones 
como categoría en el análisis del pensamiento político, permite analizar la esencia de decisiones aparentemente contradictorias. Estas reafirman una realidad hecha de luces y sombras, producida por un sujeto a la vez sapiens y demens (Maffesoli, 1993: 157), un sujeto loco, que aprende a vivir en sociedad limitando su inconsciente, el cual no depende de la determinidad, siendo producto y manifestación continua de la imaginación radical (Castoriadis, 1989: 218). Esta imaginación se asemeja a un magma de significaciones imaginarias instituidas, que no deja de moverse, de hincharse y de desinflarse, de licuar lo que era sólido y de solidificar lo que no era prácticamente nada (Castoriadis, 1989: 132). Concluimos nuestras reflexiones teóricas postulando a Nussbaum en su aproximación a la importancia de las emociones en la cultura política:

La comprensión de la relación entre las emociones (...) influirá en nuestras deliberaciones sobre cómo puede contribuir la política al florecimiento humano. Concebir lasemociones como elementos esenciales de la inteligencia humana, y no como meros apoyos o puntales de la inteligencia, nos proporciona unas razones especialmente poderosas para fomentar las condiciones del bienestar emocional en una cultura política, pues esta concepción implica que, sin desarrollo emocional, una parte de nuestra capacidad de razonar como criaturas políticas desaparecerá (Nussbaum, 2008:24).

Para comprender los vaivenes emocionales de Nussbaum, el hombre sapiens y demens de Maffesoli y el magma de significaciones que se licua y solidifica de Castoriadis, analizamos tanto parlamentarios como ciudadanos, y ciudadanos representados por aquellos parlamentarios. Inicio el análisis con los casos más bochornosos a los ojos de la ciudadanía, provocados por los representantes políticos por excelencia: los Congresistas de la República. Se proponen episodios diversos que nos pueden otorgar pistas de la contradictoria naturaleza, de los denominados padres de la patria y, a su vez, enemigos de la opinión pública. 


\section{Corrupción e inmoralidad desde la inteligencia de las emociones}

Siendo numerosos los casos escandalosos a manos de los Congresistas, para comprobar la hipótesis propuesta, se indican los casos más resaltantes en los años 2007-2010. Como primer caso tenemos la conversación interceptada entre el congresista Gustavo Espinoza y Carlos Torres Caro en julio del año 2008:

Gustavo Espinoza: Hay que buscar el bienestar del país.

Carlos Torres Caro: No, no, aquí es el bienestar de nosotros primero. Antes de pensar en el bienestar del país tiene que estar el bienestar tuyo ${ }^{6}$.

Se comprueba en este diálogo el papel de las emociones en el discurso inicuo de Carlos Torres Caro. Nussbaum explica que es la propia emoción, y no una reacción posterior a ella, lo que posee apremio y ardor. Así, las emociones tratan de adecuarse al mundo, tanto para asimilar los eventos que realmente tienen lugar como para alcanzar una visión apropiada de lo que importa o tiene valor (Nussbaum, 2008). Para Carlos Torres Caro es su bienestar el que tiene valor, es lo que importa. El destino del país se ve como un todo lejano, ideal y hasta surrealista, en cambio mi propio bienestar está al alcance de mis manos, de mis deseos, siendo inmediatamente valorado. Se piensa con las emociones. Similar situación se constata en el segundo caso, que causó un revuelo generalizado. En octubre del 2009 la congresista Rocío Gonzales fue desaforada del Congreso al ser sentenciada por haber robado energía eléctrica mediante su empresa en agravio del Estado. Fue conocida entonces como la congresista "Roba-luz", pasando a convertirse en un ícono muy negativo. En un tercer y cuarto caso se tiene actos ilegales que tuvieron severos castigos. En junio del 2007 y en marzo del 2010, las congresistas Elsa Canchaya y Tula Benítez, respectivamente, fueron desaforadas. En el

6 Diario El Comercio. 27 de julio del 2008. 
caso de Elsa Canchaya, debido a la contratación de su empleada doméstica como asesora. En el caso de Tula Benítez, por contratar irregularmente a un empleado. El quinto caso no es menos escandaloso. El congresista Álvaro Gutiérrez, en marzo del 2010, tuvo la irregular decisión de rebajar la función de uno de sus asesores a chofer para recortarle el sueldo. Son tres casos en los cuales el deseo inmediato, una vez más, toma las formas de lo inocuo. Estas prácticas, al ser descubiertas, mutan en acciones abyectas y viles, criticadas duramente, significando incluso, la expulsión del Congreso. Se sigue pensando con las emociones.

Como sexto caso, en mayo del 2008, la sociedad peruana se conmocionó con el caso del congresista Miró Ruiz, quien mató a disparos a un perro. Luego de negar rotundamente su culpabili$\mathrm{dad}^{7}$, aceptó haberlo matado, pidiendo perdón por tal incidente ${ }^{8}$. Fue bautizado por los medios de prensa como el congresista "Mata-perro", apelativo con el que sería enunciado hasta el día de hoy. Este caso demuestra la idea de inocencia que sentía el congresista en un primer momento. Al matar al perro no sentía culpa o pena alguna, lo eliminó como quien elimina a algo incómodo, sin caer en las consecuencias que este acto traería consigo. Por ello al sostener en una entrevista que "quería mucho a los animalitos" antepone a sus prácticas su ideal de inocencia, más aún, al haberlo matado, no vio en ningún momento cuán inapropiado podía ser ello en realidad. Este caso, tan sonado en su momento, representa cómo lo condenable no se limita a las prácticas de corrupción, sino que se extiende a las prácticas inmorales y crueles. Demostró por ello cuán interiorizada tiene la opinión pública peruana, la emotividad por el sufrimiento ajeno, incluso animal, y cómo es inaceptable que alguien con un cargo

7 Señaló: “No he matado a un perro, tengo animalitos y los quiero mucho (...) Esta es una cortina de humo ante los problemas del país". Diario El Comercio. 25 de mayo del 2008.

8 Declaró: "Reconozco mi mal proceder, del cual me encuentro sumamente arrepentido, sé que errar es humano..." Perú 21. Miércoles 28 de mayo del 2008. 
importante cometa tales actos de barbarie. En el séptimo caso, la congresista Rosario Sasieta fue acusada por María Medianero, quien habría sido sometida a maltratos y humillaciones, siendo obligada a lavar los pies de dicha congresista hasta en cinco ocasiones. Ella sostiene:

“(Lavaba los pies) con agua y sal, luego le daba masajes y lo hice en una tina roja que aun está en su despacho y que yo misma compré en el Mercado Central $^{9}$ (...) Sasieta me decía maldita, desgraciada, y nos obligaba a organizarle su cumpleaños y me decía: Si sale mal, te vas a meter la torta al culo" ${ }^{\prime 10}$.

Apreciamos cómo se reitera el deseo de satisfacción inmediata por parte de la congresista, aun por encima de los derechos de aquella trabajadora. ¿Sopesó las consecuencias de sus actos la congresista? Si bien cualquiera que comete tales actos sabe muy bien lo bárbaro de estos, ¿por qué actúo así la congresista? Tal vez eligió que se le lavaran los pies, ya que no sintió que tal actitud provocaría un eminente escándalo en el país entero. Este acto inmoral despertó más burlas que críticas, siendo re-bautizada con la denominación de "Pies limpios".

Como octavo caso, en marzo del 2007 salió a flote un escándalo muy grave debido al vergonzoso episodio de José Vega, quien se hizo más que famoso mediante un video en el que aparecía junto al congresista y posterior primer ministro Velázquez Quesquén ${ }^{11}$ en una fiesta en Brasil con viáticos del Congreso, la imagen de Vega fue inolvidable debido a sus connotaciones sexuales: sentado sonriente sobre otro hombre en plenas celebraciones y bailes.

Cuando aún gozaban de cierta fortaleza los partidos permitían a los políticos marcos protectores relativamente amplios.

9 Mercado tradicional del Centro Histórico de Lima que está ubicado a pocas cuadras del Congreso de la República.

10 Diario Correo. Jueves 10 de setiembre del 2009.

11 Revista Caretas (2009), Lima. 
Sin embargo, ahora que cada paso tiene que ser pensado en un contexto en que el político, al no saber bien lo que va a ocurrir con sus actos y decisiones (Grompone, 1999:291), ha terminado por emitir señales de una eminente protesta: el presente egoísta y hedonista se impone a cualquier frustración y preocupación en tiempos en los que los partidos desvanecen su legitimidad.

Noveno caso, en noviembre del 2009, Gustavo Espinoza declaró ante el Jurado Nacional de Elecciones haber estudiado en la Universidad Privada Inca Garcilaso de la Vega, aunque nunca lo haya hecho. Esto trajo consigo una seria reflexión en torno a comprobar fehacientemente lo que los congresistas sostienen en su hoja de vida. El mensaje que el ciudadano resignificó a partir de este hecho, no fue sólo el de tildarlo de mentiroso, sino el de concebirlo como un eminente tonto e ignorante, que no había sido capaz de cursar estudios universitarios. Muestra de ello es el titular del Diario Perú 21 del día 10 de noviembre de 2009, que señala así: "No acabó el colegio: más mentiras en su hoja de vida", y a ello se le añadía una foto de este congresista con orejas de burro. Las emociones demuestran no ser fuerzas ciegas que carecen de discernimiento e inteligencia, sino que poseen un alto contenido cognitivo-intencional (Nussbaum, 2008:32), tal como lo demuestra el ímpetu por declarar cierta educación superior, aun a costa del fraude.

Como décimo caso encontramos al congresista José Anaya, que fue descubierto adulterando recibos para justificar sus gastos operativos, entre los cuales se hallaban recibos de haber comido el emblemático plato "pollo a la brasa", lo que fue suficiente para ser bautizado con el apelativo de "Come-pollo"12. Los gustos y placeres se anteponen a las consecuencias, aunque se trate de un simple plato de comida. Sin embargo si se considera que el pollo

12 Cierto usuario de la pagina web del Diario Perú 21 sostendría: “La vergüenza que se siente por este congresista, es de lamentar que alguien así nos represente, un don nadie." 
a la brasa resulta ser, tanto uno de los platos más consumidos en el Perú como uno de los más simbólicos en el ámbito de la celebración y reunión en restaurantes de diversas ciudades del país, se comprueba el poder de la subjetividad que impone sus deseos más inmediatos teniendo como elemento crucial, un plato tan representativo en el Perú. La ciudadanía antes que criticar este delito se mofó de las circunstancias del mismo.

En el décimo primer caso, el 13 de diciembre de 2009, el presidente del Congreso, en aquel entonces Alba Castro, autorizó un subsidio de 15 mil dólares para un espectáculo de la artista Fabiola de la Cuba. Al día siguiente anunció que el dinero sería devuelto de sus ingresos correspondientes a su gratificación de diciembre de aquel año, el integro de su compensación por tiempo de servicios y un descuento de sus remuneraciones de enero a julio del año $2010^{13}$.

El símil con nuestra hipótesis es clara: al inicio no era sino algo inofensivo, que aun siendo presidente del Congreso, no llevaría a ningún problema. Al menos eso creía. Apenas un día después, la presión mediática fue tan rotunda que como si su conciencia hubiera sido atacada por un supremo remordimiento, decidió enmendar su error, aun a costa de sus propios ingresos. Aceptó la injusticia de sus actos, "sacrificando" su propio bienestar, para demostrar su arrepentimiento. Se crea así un entorno menos sensible a las pautas de una democracia representativa y más proclive al aprovechamiento cínico de ventajas y oportunidades (Vargas-Machuca, 2008: 172). Estamos frente al esquizofrénico que citaba Lechner (1988:73), el cual está condenado a vivir en un presente perpetuo con el que los diversos momentos de su pasado y, según se constata, del pasado de los demás casos de corrupción que abundan antes que el suyo propio, tienen escasa conexión. Sostiene el autor:

13 Diario PERÚ 21. 8 de febrero del 2010. 
Este esquizofrénico no filtra el presente, por lo que tendrá una experiencia mucho más intensa, pero finalmente abrumadora. Vive intensamente el instante, pero al precio de petrificarlo (...) se ahoga en una inmediatez sin fondo. (Lechner, 1988: 73)

Discutamos brevemente la paradójica relación entre el acto pre-operatorio al momento de cometer delitos e infracciones diversas y las consecuencias del mismo. Si cometo una acción perversa, vil, infame e injusta, a la larga mi acción es inofensiva, casi inocente e insulsa ya que forma parte de un radio de acciones que son el común performativo cometidas por parlamentarios como yo. Esta reflexión cobra sentido si reconocemos cómo las emociones se centran en nuestros objetivos y representan el mundo desde ahí antes que desde un punto de vista estrictamente imparcial (Nussbaum, 2008:33). El castigo si bien puede ser duro, al punto de ser desaforado y condenado penalmente, la intensidad y regularidad con que se cometen nos convence de una acción más allá de lo disfuncional. Se trata de una acción que sigue dentro de los márgenes de lo inofensivo para quienes la cometen. Estos márgenes se ubican en lo que Mujica señala como los mecanismos de corrupción, los que lejos de salir del sistema permiten a los actores entrar en él: la corrupción resulta un vehículo central para construir alianzas, redes y grupos, complicidades, redes de contactos que funcionan como un capital central en el terreno político local (Mujica, 2009).

Así se fortalece una cultura que se organiza éticamente en torno a mediaciones y conciliaciones con todo tipo de actos inmorales e ilegales (Silva Santisteban, 2008:121). Este tipo de organización demuestra la capacidad del ser vivo para transformar el accidente o la perturbación en nueva organización (Castoriadis, 1989:89). En efecto, hablar de corrupción no es hablar de un fenómeno antisistémico que corroe las bases de lo que serían nuestras instituciones estatales, por el contrario, forma parte de su funcionamiento. Siendo así, ¿cómo comprender la sorpresa generalizada en una población que cultiva en sus propios motivos 
cotidianos la tan famosa herramienta de movilidad social denominada "la criollada" (o su versión más anodina y cotidiana: "la pendejada")?

Si deseamos comprender un poco más los constructos intersubjetivos que sostiene la población, es necesario ahondar en los múltiples elementos que intervienen en este complejo proceso. Ahora aproximémonos al juicio crítico del ciudadano, y cómo este juicio va desvaneciendo la tensión entre lo inicuo y lo inocuo.

\section{Re-creaciones de la perversión política en la ciuda- danía}

¿Cómo entender la resistencia aparentemente estoica por parte de los ciudadanos a tantos sucesos que atacan la institucionalidad política del Perú? ¿Cómo explicar aquella concatenación constante y multiforme que difícilmente se detiene y que, por el contrario, crece, evoluciona y se transforma en peores y mayores escándalos? Asistiríamos a la formación de una sociedad horizontal con un centro integrado y una periferia donde no existen mecanismos de integración claros (Calderón, Hopenhayn, Ottone, 1996: 54), dando cabida a la desafección y despolitización de la ciudadanía y de agudización de problemas de representación y legitimidad en la relación entre dirigentes y dirigidos, creciendo de este modo el abstencionismo (Calderón, Hopenhayn, Ottone, 1996: 53). Ello sirve como caldo de cultivo para el surgimiento de un ciudadano consumidor-espectador que miraría la política como si se tratara de la actuación de un cuerpo separado y especializado (Calderón, Hopenhayn, Ottone, 1996: 54). Dicha actitud lo hace inmune al "asco moral".

En el Perú de los últimos años se ha perdido el asco moral como forma de consolidar las relaciones internas de cohesión de una sociedad y se ha implantado un trastrocamiento de valores que, a su vez, anestesia a los peruanos que escurridamente se 
entregan a los hedores de la corrupción (Silva Santistevan, 2008: 122). Dichos hedores no son tan perceptibles, al haberse convertido de un magma que se hincha (hiede) y se desinfla (no hiede), licua lo sólido de la crítica descarnada y el descontento social para solidificar la imperceptibilidad que antes no se hubiera creído posible.

Esta imperceptibilidad tiene otro factor. Seguimos, a manera de símil, la división hecha por Foucault (2001) entre el monstruo, el correccionario y el onanista. Interpretamos al monstruo de Foucault -que infracciona las leyes en su misma existenciacomo monstruo político, derruido en su ética e inclusive en su estética. Este ser nefasto era la excepción por definición, presto a ser no sólo criticado, sino destruido desde sus abyectos cimientos: un ser incapaz de ser reincorporado a la vida púbica (Foucault, 2001:61-64). En cambio el correccionario o individuo a corregir, en la perspectiva de Foucault, pasa a ser un fenómeno corriente, al punto que es en cierto modo regular en su irregularidad, siendo siempre difícil de determinarlo: nunca se podrá demostrar que el individuo es incorregible, encontrándose en el límite de la indecidibilidad. Se trata de un monstruo trivializado y empalidecido. Finalmente el onanista o masturbador, como control de la carne en los movimientos elementales de la concupiscencia. La conclusión del autor es que el espanto que el monstruo ponía antaño a la luz de un día excepcional es deslizada bajo las pequeñas anomalías de todos los días del masturbador (Foucault, 2001: 299). El magma ha pasado de ser sólido a licuarse, escurriéndose entre los dedos de la percepción. Al político malévolo y monstruoso, se le toma por mero sujeto a corregir para luego ser considerado como una pequeña anomalía representada en las noticias periodísticas publicadas continuamente en diversos periódicos, desde los más populares hasta los más serios. Esto nos lleva a pensar la corrupción e inmoralidad en la coyuntura política como un indiscutible peligro para la democracia en nuestro país debido a la insensibilidad de ser percibido. Sin embargo, ¿cuán insensible a este fenómeno es la ciudadanía? 
Para comprender esta sensibilidad trastrocada de la sociedad ante las prácticas políticas inicuas es necesario considerar diversos factores. No tiene peligrosidad aquello que el ciudadano conoce muy bien, y si hay algo que reconoce, es esa "clase política corrupta". Es necesario considerar que la medida de la peligrosidad está en relación con la capacidad defensiva de quien está en peligro, por ello la sola fuerza exterior no define la intensidad del miedo -y el eventual espanto al monstruo del cual se refirió Foucault-; la define, en cambio, su relación más o menos precisa con las fuerzas del sujeto agredido (Ojea, 2002: 32). Se dirían a sí mismos: no me dan miedo, si bien me importunan, a la vez me divierten. Prueba de ello son las denominaciones expuestas anteriormente: la "Roba-luz", "el Mata-perro", el "Come-pollo", la "Pies-limpios", entre otros. Los odios dan paso a la conformidad de las prácticas inicuas, transformándose en prácticas inocuas ${ }^{14}$ o inofensivas a la percepción de la ciudadanía. Temible reflexión si se considera que el rendimiento moral de la democracia representativa está en función de la mejora del arbitrio de los ciudadanos frente a los liderazgos concurrentes y del alcance de las demandas ciudadanas satisfechas (Vargas-Machuca, 2008:154). A la larga caducan las críticas y las amonestaciones sociales. Tal vez aquí yace el nudo de todo este debate.

Tal vez estemos en tiempos en que, según explica Zizek (2005: 8), la amenaza no es la pasividad, sino la pseudoactividad, la urgencia de "estar activo", de "participar", de enmascarar la vacuidad de lo que ocurre. Lo verdaderamente difícil es retroceder, retirarse. Tal pseudoactividad es prefigurada por el hiperconsumo, dando a luz a un homo consumericus que se deja caer en brazos de la tiranía de la belleza, la individualización extrema, el do-

14 El juego de palabras inicuo-inocuo busca relacionar metafóricamente la inclinación entre las prácticas injustas y su móvil de la creencia que resultan ser prácticas inocuas o inofensivas para quien las practica, motivo por el cual las hace. El riesgo al cual se adscribe y hace caso omiso, es parte de esa inmediatez de las emociones de las que he tratado líneas atrás. 
paje generalizado y la dictadura del orgasmo (Lipovetsky, 2007: 250-293). Siendo la política un motivo de discordia, debido a la corrupción clientelista y al descrédito moral, se podría decir que los ciudadanos han llegado al punto de sufrir ciertos trastornos cotidianos provocados por las mayores carencias de los tres tipos de sentido enunciadas por Laidi (1997: 25): de fundamento como proyecto colectivo, de unidad como conjunción de imágenes del mundo dentro de un esquema coherente y de finalidad como proyección hacia algo que se cree mejor. Si se considera que representar es reflejar una realidad, reproduciéndola a escala (VargasMachuca, 2008:146), la máxima que sostiene que la democracia representativa representaría el modelo de democracia con mayor productividad política y alcance moral que cualquier otro modelo alternativo (Vargas Machuca, 2008: 156) tiende a ofrecernos un modelo bizarro de la inmoralidad política. Siendo la tarea de la política acoger los deseos y los malestares, las ansiedades y las dudas de la gente, e incorporar sus vivencias al discurso público (Lechner, 2002:12), este paisaje bizarro de la política engarzaría a representantes y a representados.

El acto de acusar es un acto de catarsis, una posibilidad de satanizar al otro. La comicidad y el gusto por la burla hacia el otro no sólo esconden una situación de aparente diversión, es también un modo de resignificar el rechazo hacia el otro.

En el Congreso peruano más resuena por su escándalo bochornoso y el ataque enfocado a sus representantes, mas no hacia al acto en sí. Genera la risa inmediata pero no la reflexión. Poseen la etiqueta atractiva del acto vergonzoso. No sólo se canibaliza al otro, sino que se canibaliza al "padre de la patria". El rol estético de los medios de comunicación en la perversión de la política es crucial. Como se vio, los titulares diversos en la televisión y en la prensa deparan un consumo desbocado de prejuicios y perversiones a través de denominaciones cómicas a los actos de corrupción. La influencia que se pudiera ejercer sobre la opinión pública se hace a través de la televisión y la radio, los medios 
escritos y las imágenes diversas del spot publicitario. La sociedad del consumo, a través de la ironía y el chisme, celebra los desvaríos y desajustes políticos gracias a que la política ha sabido acoger las ansiedades de sus ciudadanos: lo logra a través del vilipendio mordaz. Las condiciones son favorables y el espectáculo cómico en torno a la vedette política acrecienta ${ }^{15}$, facilitando que el ciudadano y ciudadana pueda ampararse en aquel fenómeno, que más allá de ser un mero chivo expiatorio, provoca a la vez una triple sensación de burla-molestia-identificación. Los procesos discursivos propios de un ejercicio cabal de la representación declinan en beneficio de lo inmediato y espectacular, de lo excéntrico e impactante (Vargas-Machuca, 2008:174), de una política light que neutraliza todas las tensiones y controversias (Lechner, 2002: 34).

Es posible reconocer una peculiar dialéctica entre la imitación y la subversión (Quijano, 1999) de aquella grotesca instancia de la "criollada", capaz de hacer del ciudadano consumidor-espectador una suerte de crítico y a su vez reproductor de dichas prácticas inicuas. Nada más lejos del minimalismo moral que postulaba Walzer, en que la norma no debería servir a ningún interés particular, regulando los comportamientos de todos de una manera ventajosa y correcta (Walzer, 1996: 39). Según explica Castoriadis, esta norma de identidad llega a ser eso que ella misma decreta: "identidad de la norma consigo misma, puesta por la norma, para que pueda haber norma de identidad consigo mis-

15 Ya lo dice aquella canción de Lizandro Meza, ahora cantada por el exitoso conjunto de música tropical peruano Grupo 5, que sonó en las diversas radios de moda en los años 2009 y 2010: "Pero para político no", en donde se ridiculiza y se rebaja el oficio de político. En efecto se cree que en el Perú la política está plagada de un virus que la corroe desde adentro mismo: la corrupción. Cierto usuario de la página web de videos You Tube, opina acerca de esta canción: Tiene razón el pata de acá abajo: para qué pagar para políticos, hay pura basura ahí, como el "Mataperros", la "Cocalera", la que hace lavar sus pies a sus empleadas, la "Robaluz", el "Comepollos" y más, más. Me entiende la gente de Perú. Este tipo de discurso tiende a generalizarse y a repetirse de acuerdo con la sintonía anti política de la canción. 
mo" (Castoriadis, 1989: 72). Este bizarro contexto corrompe la capacidad de la sociedad de intervenir sobre su propio desarrollo, el cual depende de la auto-imagen que ella tenga de si misma, de una imagen fuerte del Nosotros como actor colectivo (Lechner, 2002:12). Se trata de una especie de "crisis del sentido" en donde esa discrepancia mal vivida entre el concepto y la realidad, manifiesta un juego de evitación muy peculiar (Laidi, 1997:39). Los ciudadanos apoyan y manifiestan una actitud crítica frente a la corrupción pero, a la vez, reniegan de la política y la soslayan por entero. Se alimentan no del vacío, sino de un reciclaje de críticas, prejuicios y risotadas, todo ello como catarsis para un país con desigualdades considerables y en muchos casos, desorbitantes. Asistimos, pues, a una nueva perfomance de la democracia basada en imágenes, emociones y no en programas o en el consenso sobre políticas (Vargas-Machuca, 2008:174), de modo que se va desvaneciendo la política, estableciéndose una "tolerancia desublimada" a las aspiraciones que, desprendidas de un contexto más amplio de relaciones, no consiguen finalmente cuestionar los mecanismos centrales de poder (Grompone, 1999:53).

\section{Conclusiones}

Llegados a este punto, ¿podemos decir que dichas condiciones de la política actual, ataviadas de escándalos y bochornosos episodios, mantienen, en cierto modo, unida a la sociedad? Castoriadis refiere:

Lo que mantiene unida a una sociedad es el mantenimiento conjunto de su mundo de significaciones. Lo que permite pensarla en su ecceidad, como esta sociedad y no otra, es la particularidad o especificidad de su mundo de significaciones tanto institución de este magma de significaciones imaginarias sociales, organizado precisamente así y no de otra manera (Castoriadis, 1989: 313).

Nuestra ecceidad nos remite a diferenciarnos de cualquier otra realidad, concibiéndonos en el seno de un mundo de significaciones que nos une en tiempos en los cuales la sociedad que 
se sabe fragmentada, una identificación que cobra un sentido de individualidad en la diferencia, superando la estratificación y movilidad de raza y estamento (Ríos, 2006: 385). Entre esos elementos que tienden a unirnos, se halla esa perversión de la política que si bien la une, también la desvirtúa como sociedad. Creer en un cambio de esta situación no es utópico. La realidad social no es inflexible, es un magma de significaciones en el que cabe la posibilidad de separar los conceptos de lo injusto y lo inofensivo, sometiendo a cualquier acto de corrupción e inmoralidad -antes que la risa generalizada como anécdota superficial- a su esencia más ínfima: el de su execrable e inmediata amonestación. La abyección de tales actos debe ser reconocida por representantes políticos y ciudadanía representada, dando cabida a una sociedad en que la política sea vista no como sus manifestaciones negativas, sino como sus más importantes posibilidades de representatividad democrática. Sin embargo, el camino recorrido hasta el día de hoy, en lugar de acercarnos a una solución, nos aleja.

Es hora de ponerle fin a los alegatos tímidos y díscolos. La gravedad de las prácticas inicuas deberá ser sentida en la intimidad de las emociones ciudadanas, incluyendo a los adolescentes menores de edad. Tanto investigadores como teóricos deben flexibilizar la idea tradicional de la neutralidad valorativa, para que la ciencia política pueda afrontar mejor los problemas como la crisis de las instituciones democráticas (Cansino, 2008:39). En esta línea, es urgente el fortalecimiento de la institución de la representación democrática del Perú, así como la destrucción de la institucionalidad de la perversión ética de la política. En relación a ello Henry Miller nos ofrece una importante reflexión: Hablamos de la defensa de nuestras instituciones, de nuestra manera de vivir (...) pero hay cosas que deberíamos destrozar con nuestras propias manos (Miller, 1965:10). El problema, en boca de Castoriadis, yace cuando estamos frente a tal absurdo contemporáneo en que ni la revelación de un caos ético inminente puede "sacudirnos", al dejar de ser absurdo: ya no hay ningún polo de lo no absurdo, ante el cual, al oponerse, pudiera revelarse fuerte- 
mente como absurdo. Es negro pintado sobre negro (Castoriadis, 2008:22). Para abordar el problema, el ágora de la teoría política debe dejar de ser exclusiva para "políticos de carrera" y dar paso a las vivencias y prácticas políticas de la cotidianidad social que hemos demostrado: miedos convertidos en irónicas risas, espasmos trágicos en torno a la corrupción e inmoralidad, que dan paso a la tolerancia y aceptación.

En el Perú lo político como ideario democrático no existe. Existen políticos de carne y hueso que reflejan el significado de lo que se piensa como político. La política en el Perú es una esfera capaz de convivir con el festejo de lo criollo y lo pendejo, de lo huachafo y lo bonito, de lo medianamente correcto y lo medianamente incorrecto. En fin, todo eso que hace del contexto político peruano, un show del divertimento y el relajamiento. Se vive para criticar, se vive para reír. En este sentido, en palabras de Zizek, es necesario retirarse de una nociva actividad participativa, que lejos de criticar el estado "natural" de las cosas, las robustece y las retroalimenta. En lugar de dormir en los sueños de otros (Castoriadis, 2008:32) es necesario reflexionar sobre la necesidad de la comprensión de lo privado y lo lúdico; desde lo onírico hasta lo real; desde lo sapiens hasta lo demens. La reflexiones en torno a la política deben ir más allá de la ciencia política clásica, la cual yace sin ideas ni sustancia, atrapada en saberes inútiles para aproximarse a la realidad en toda su complejidad (Cansino, 2008:7). Esa ciencia política, concluye Cansino, le ha dado la espalda a la vida por lo que sólo pueden brotar datos inútiles e irrelevantes: el pensamiento político, la sabiduría política, hay que buscarlos en otra parte (Cansino, 2008: 8). Habiéndose concluido recientemente las elecciones presidenciales para el período 20112016 en el Perú, es necesaria la crítica pormenorizada y no amnésica en base al análisis comprensivo que dé cabida al mundo de las emociones en la política. 


\section{Bibliografía}

Diarios de circulación nacional:

Diario Correo. Jueves 10 de setiembre del 2009

Diario El Comercio. 25 de mayo del 2008

Diario El Comercio 27 de julio del 2008

Diario Perú 21. 8 de febrero del 2010

Diario Perú 21. 10 de noviembre del 2009

Diario Perú 21. 28 de mayo del 2008

\section{Material virtual}

Compañía peruana de estudios de mercado y opinión pública S.A.C. Revisado el 20 de diciembre del 2009. En www.cpi.com.pe

Diario Perú 21. Revisado el 30 de noviembre del 2009. En www.peru21.pe Ipsos Apoyo Opinión y Mercado S.A. Revisado el 10 de mayo y el 25 de junio del 2010. En www.ipsos-apoyo.com.pe

Mujica, Jaris (2009): “Ni mafias, ni cárteles, ni clientelas”. En Argumento Revista de análisis social del IEP. En www.revistargumentos.org.pe

Revista Caretas. Revisado el 30 de noviembre del 2009. En www.caretas. com.pe $/$ Main.asp?T=3082\&idE $=713 \&$ idS $=230$

YouTube - Broadcast Yourself. Revisado el 8 de diciembre del 2009. En www.youtube.com

\section{Fuentes teóricas}

Arias, César (1996): Perú: entre la utopía y el cinismo. Lima: Fundación Friedrich Ebert.

Calderón, F.; Hopenhayn, M. y Ottone, E. (1996): Esa esquiva modernidad. Caracas, Nueva Sociedad.

Cansino, César (2008): La muerte de la ciencia política. Buenos Aires, Sudamericana.

Castoriadis, Cornelius (1989): La institución imaginaria de la Sociedad, Tomo II. Barcelona, Tusquets Editores. 
Castoriadis, Cornelius (2008): Ventana al caos. Buenos Aires, Fondo de Cultura Económica.

Foucault, Michel (2001): Los anormales. México D.F., Fondo de Cultura Económica.

Grompone, Romeo (1999): Las nuevas reglas del juego. Lima, Instituto de Estudios Peruanos.

Laidi Zaiki (1997): Un mundo sin sentido. México D.F. Fondo de Cultura Económica.

Lechner, Norbert (2002): Las sombras del mañana. Santiago, LOM.

Lechner, Norbert (1988): Los patios interiores de la democracia. Santiago, FLACSO.

Lipovetsky, Gilles (2007): La felicidad paradójica. Barcelona, Anagrama.

López, José Ignacio (2007): Adiós a Mariátegui. Lima, Fondo Editorial del Congreso del Perú.

Maffesoli, Michel (1993): El conocimiento ordinario. México D.F. Fondo de Cultura Económica.

Miller, Henry (1965): Un domingo después de la guerra. Buenos Aires, Santiago Rueda.

Molinari, Tirso (2006): El fascismo en el Perú. Lima, Fondo Editorial de la Facultad de Ciencias Sociales-UNMSM.

Nussbaum, Martha (2008): Paisajes del pensamiento. Barcelona, Paidós.

Ojea, Fernando (2002): Angustia y sentido. Málaga, Colección Ítaca.

Planas, Pedro (2000): La democracia volátil. Lima, Fundación Friedrich Ebert.

Quijano, Aníbal (2006): “Don Quijote y los molinos de viento en América Latina", en Investigaciones Sociales. Año X N 16 (pp. 347-368) Lima, UNMSM IIHS.

Ríos, Jaime (2006): Sociología de Lima. Lima, Fondo Editorial de la Facultad de Ciencias Sociales-UNSM.

Silva Santistevan, Rocío (2008): El factor asco. Lima, Red para el Desarrollo de las Ciencias Sociales en el Perú.

Walzer, Michael (1996): Moral en el ámbito local e internacional. Madrid, Alianza.

Zizek, Slavoj (2005): La suspensión política de la ética. México D.F. Fondo de Cultura Económica. 